\title{
Tuboendometrioid Metaplasia
}

National Cancer Institute

\section{Source}

National Cancer Institute. Tuboendometrioid Metaplasia. NCI Thesaurus. Code C127937.

Replacement of the endocervical-type epithelium of the cervix by benign tubal or endometrioid epithelium. 